\title{
Limited Resources and Complicated Procedures Maternal Health Problems of Urbant Migrants in Region
}

\author{
Nuzulul Kusuma Putri, Ratna Dwi Wulandari and Nyoman Anita Damayanti \\ Faculty of Public Health Universitas Airlangga, Mulyorejo, Surabaya, Indonesia \\ \{nuzululkusuma,ratna-d-w,nyoman.ad\}@fkm.unair.ac.id
}

Keywords: Maternal health problems, migrants, urban

Abstract: $\quad$ The generally high maternal mortality rate in Indonesia mostly happens in the urban regions. The physical accessibility of healthcare services in urban areas does not seem to guarantee the healthy pregnancy. This also happens in Surabaya which has contributed to more than $16 \%$ of the maternal deaths in East Java. This study aimed to explore any maternal health problems that are faced by urban migrants in Surabaya and how community reacts to these problems. This was an exploratory study in 2 industrial subdistricts, Medokan Ayu and Gunung Anyar, which are mostly inhabited by urban migrant workers. The total population of midwives in both Public Health Centers was asked about their experiences in handling maternal health in urban migrant population. A serial of Focus Group Discussion participated by health and social workers identified the existing problems. This study shows that the main maternal health problems are the administration requirements in accessing free healthcare service using national health insurance. Administration regarding citizens' registration is not yet ready to implement the portability principles of National Health Insurance. The movement to the hometown of expectant mothers in the last trimester still happens and ruins the maternal record and monitoring postpartum plan in migrant areas.

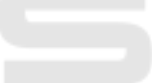

\section{INTRODUCTION}

At the end of the Millennium Development Goals 2015, maternal health still had significant problems in healthcare. The World Health Organization reported that even if there was progress in the achievement of this fifth goal, there was still many unfinished work. Even though maternal mortality fell impressively by more than $40 \%$, it still remains short of the MDGs target. WHO fact sheets in November 2016 listed that $99 \%$ of women's deaths during pregnancy, childbirth and the postpartum period occured in developing countries. It is higher in rural areas and among poorer communities.

Indonesia is a developing country in Asia also faced with a high number of maternal deaths. While the number of expectant mothers labored in a health facility improved by $86 \%$ in 2016 , there were still 4,912 mothers who died when bearing their child. This number remains high by 1,712 cases only until the mid-year of 2017. Surprisingly, this maternal mortality mostly happens in provinces near the nation's capital city which should be having the least disparity in healthcare facilities.
East Java province is the province with second highest mortality rate in Indonesia. The maternal death rate in this province reached 500 deaths per 100,000 births in 2016. This number was higher the national maternal rate by only 340 maternal deaths per 100 thousand births. Most of the maternal deaths in East Java province happened in its capital city, Surabaya. The existence of many hi-tech health facilities with well-qualified obstetricians in Surabaya seems not to guarantee that pregnant women get through their pregnancy, childbirth and postpartum period safely.

As a large city that offers an enormous number of job vacancies, Surabaya has succeeded to attract migrants' workers from its surrounding city. Most of these migrant workers live in Surabaya without updating to 'living in a city' in their citizenship identity. In Indonesia, updating to 'living in a city' in the citizenship identity brings many citizenship benefits including social health insurance. Considering the decentralization, social health insurance for citizens is paid by the local government in every district. Moreover, migrants are reluctant to some issues of civil registration which are then related to equity in accessing healthcare. 
Migrant status is one of social determinants of health which can intersect with other determinants to adversely affect both health care access and health outcomes (Fleischman et al., 2015). Culturallysensitive primary care is believed to have an important role in delivering accessible, high-quality care to migrants in vulnerable situations (O'Donnell et al., 2016). Even though the number of studies about migrants' health access is rising, in our knowledge, there is no study that explains the role of each sub-system in primary health care service. This study aims to explore any maternal health problems that were faced by urban migrants in Surabaya and how the primary healthcare sub-system reacted to those problems.

\section{METHOD}

This is an exploratory study in 2 industrial subdistricts, Medokan Ayu and Gunung Anyar. Both of these subdistricts are inhabited by a huge number of urban migrant workers. The total population of midwives in both Public Health Centers was asked about their experience in handling maternal health in the urban migrant population. Pair of Focus Group Discussion which was participated by midwives and social workers in each Public Health Center identify the existing problems in each subdistrict. These FGDs were held in two different sessions in order to prevent the fear of each group to state the real problems. Each FGD discussed the existing problems due to maternity care in the urban migrant workers that were encountered by health workers in Public Health Center, social workers, and the urban migrants. The results were then compared between the Public Health Service to find the exact problems in managing the maternity health of urban migrants.

\section{RESULT}

There are at least three central keypersons which are involved in the management of maternity health in the primary care level. These groups are the health workers in Public Health Centers as the supply side which is giving the treatment, the social workers who reside in the same community of urban migrants, and the urban migrants themselves. These people are interrelated with each other in their different roles. The social workers have an important role to connect the urban migrants to the health workers. Even though they work for free, they still have to be able to communicate with the urban migrants when health workers find it hard to reach the urban migrants.

On the other hand, national health insurance in Indonesia is partially social health insurance. Although there is part of the population who should pay the premium by themselves, most of participants are a reluctant population which is why the premium is paid by the government. Even though it is compulsory for every Indonesian citizen to be registered, there is still a large number of the population uncovered by National Health Insurance. Data from BPJS Kesehatan, the insurance agency of National Health Insurance, shows that the majority of the unregistered population is informal workers. They must pay the premium by themselves, considering that they do not have employers. All of these groups exist in both subdistricts of our study.

Most of the urban migrants do not have any identity documents based on their recent residence. They tend to still keep their identity belonging to their hometown. For those who have already registered as national health insurance participants, they have no risk in accessing free healthcare services if they have adjusted the location of their primary healthcare facility according to their recent domicile. When they do not change the primary healthcare due to their residency, they cannot use the coverage and must pay the healthcare services. Moreover, the rest of the urban migrants with no national health insurance coverage mostly work as blue-collar workers with a low income. This informal workers' participation is becoming a crucial issue in universal health coverage. The risk in not being able to access free healthcare service is doubled in this group when they do not have identity documents which belong to their recent residence. Table 1 points out which problems existed in managing maternity health of urban migrants in both subdistricts.

Table 1: Problems found in managing the maternity health of urban migrants.

\begin{tabular}{|c|c|c|}
\hline & Medokan Ayu & Gunung Anyar \\
\hline & \multicolumn{2}{|c|}{ Problems } \\
\hline $\begin{array}{l}\text { Health } \\
\text { workers }\end{array}$ & $\begin{array}{l}\text { The fetus condition } \\
\text { is always } \\
\text { considered by the } \\
\text { referral hospital in } \\
\text { accepting the } \\
\text { expectant mother. } \\
\text { All of referral } \\
\text { hospitals tend to } \\
\text { refuse any mothers }\end{array}$ & $\begin{array}{l}\text { Health workers } \\
\text { generally took too } \\
\text { long time waiting } \\
\text { for family approval } \\
\text { to refer. There } \\
\text { were many internal } \\
\text { family } \\
\text { considerations that } \\
\text { actually hinder the }\end{array}$ \\
\hline
\end{tabular}




\begin{tabular}{|c|c|c|}
\hline & $\begin{array}{l}\text { with a poor } \\
\text { condition of fetus. } \\
\text { For mothers who do } \\
\text { not have any health } \\
\text { insurance, are poor, } \\
\text { or have no identity } \\
\text { card, the midwives } \\
\text { of the Public Health } \\
\text { Center who } \\
\text { accompany the } \\
\text { mother during the } \\
\text { referral process are } \\
\text { often detained as a } \\
\text { "hostage" to } \\
\text { guarantee there will } \\
\text { be a person who } \\
\text { takes the } \\
\text { responsibilities of a } \\
\text { mother. }\end{array}$ & $\begin{array}{l}\text { referral process. } \\
\text { This habit risks the } \\
\text { patient's condition. } \\
\text { The majority of the } \\
\text { patient's family } \\
\text { refused to be } \\
\text { referred because of } \\
\text { additional costs } \\
\text { such as transport } \\
\text { cost and no } \\
\text { guardian. }\end{array}$ \\
\hline $\begin{array}{l}\text { Social } \\
\text { workers }\end{array}$ & $\begin{array}{l}\text { Some mothers and } \\
\text { their families never } \\
\text { socialize with their } \\
\text { neighbors because } \\
\text { of time spent } \\
\text { working or even } \\
\text { being an introvert } \\
\text { person. It makes } \\
\text { social workers find } \\
\text { it hard to help the } \\
\text { migrants workers. } \\
\text { There is no clear } \\
\text { specific procedure } \\
\text { for social workers } \\
\text { in helping mothers } \\
\text { to access healthcare } \\
\text { facilities especially } \\
\text { in } \\
\text { condition. }\end{array}$ & $\begin{array}{l}\text { Social workers } \\
\text { often meet mother } \\
\text { and her family who } \\
\text { refuse to be } \\
\text { referred due to } \\
\text { their fear about the } \\
\text { potential high cost } \\
\text { of care and the } \\
\text { guardian's } \\
\text { opportunity cost. } \\
\text { Social workers are } \\
\text { often suspected by } \\
\text { hospitals as } \\
\text { middleman who try } \\
\text { to take financial } \\
\text { benefit from } \\
\text { patients since they } \\
\text { do not have any } \\
\text { identity card as } \\
\text { social workers. }\end{array}$ \\
\hline $\begin{array}{l}\text { Urban } \\
\text { migrant }\end{array}$ & $\begin{array}{l}\text { The white-collar } \\
\text { workers and their } \\
\text { family members } \\
\text { already covered by } \\
\text { their employer with } \\
\text { health insurance. } \\
\text { The main problems } \\
\text { in this group are } \\
\text { that the Public } \\
\text { Health Center could } \\
\text { not detect their } \\
\text { health condition } \\
\text { since most of them } \\
\text { never controlled } \\
\text { their health in }\end{array}$ & $\begin{array}{l}\text { Blue-collar } \\
\text { workers seem to } \\
\text { have limited } \\
\text { information about } \\
\text { national health } \\
\text { insurance. BPJS } \\
\text { Kesehatan only } \\
\text { socializes to a } \\
\text { small number of } \\
\text { this group. }\end{array}$ \\
\hline
\end{tabular}

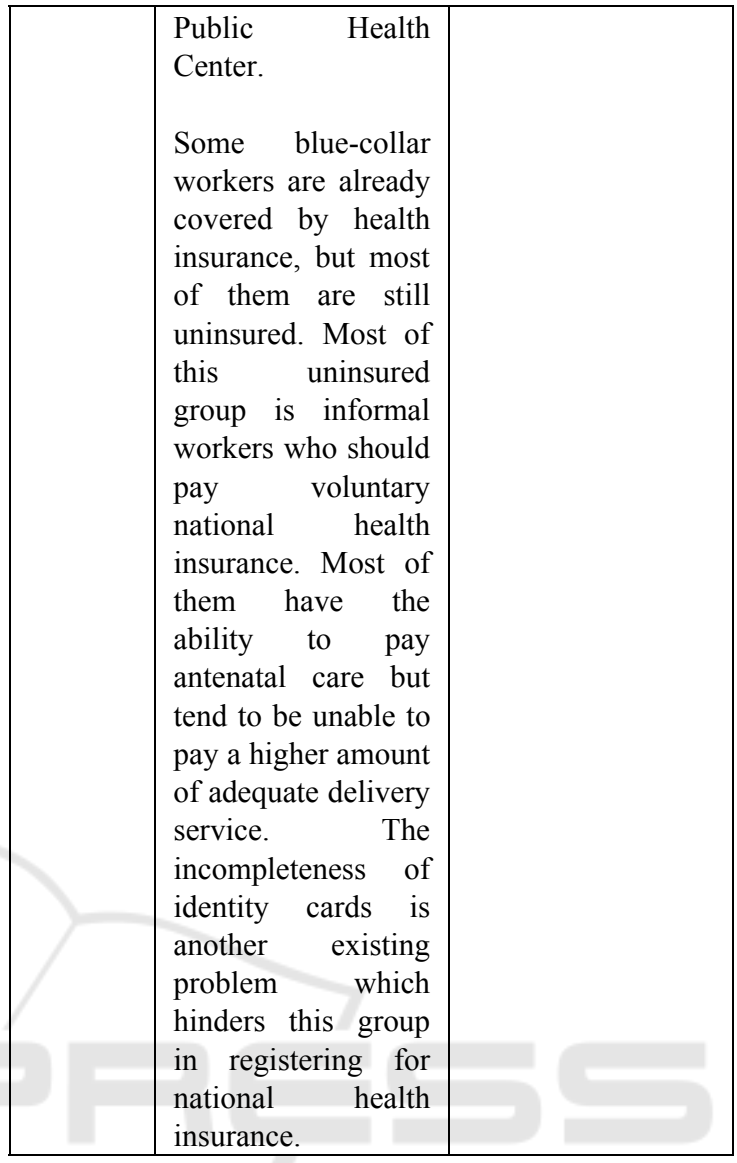

Table 1 show that each subject which is involved in managing the maternity health of urban migrants in the primary level has their own problems. Health workers have problems in both communicating with urban migrants and in communicating with referral systems. It turns out that the hospital is also considering the condition of the fetus in accepting maternal referral. This problem is often experienced by the midwives due to the fact that the treatment costs of neonates are very high and not all of the hospitals in Surabaya have a neonatal intensive care unit. The midwives should also be ready to work harder in accompanying expectant mothers who do not have any identity documents, but need to be referred to hospital. Another challenge in managing maternity health in this population is how health workers could communicate with this group remembering that this group does not actively report their existence to the recent residence government. In this case, the Public Health Center is the only solution to connect both of these parties. Other potential problems exist when the Public Health Center is already connected to the urban migrants. Besides the inability of urban migrants to provide 
the exact identity documents, the movement to hometown of expectant mothers in their last trimester still happens. This ruins the maternal record and monitoring plan of postpartum in the migrant area.

\section{DISCUSSION}

There are several types of migration. This paper uses the type of migration which refers to the rural-tourban migrants in a country. This usually happens in the cases of better economic inducement offered by the urban region. People speculate that they will obtain a preferable job in the urban region, both in blue- and white-collar work. On the other hand, rural-to-urban migrant workers are an underrepresented group in Indonesia's national health insurance system. Based on our study, migrant workers with blue-collar jobs tend not to be covered by any health insurance. We found that their "urbanrural duality" has the consequence of their absence in national health insurance. The "urban-rural duality" appears when the migrant workers do not update their identity documents with their current domicile and still belong to their localities. When people have urban-rural duality, if their identity belongs to the rural side, it will hinder them in using facilities which need urban identity.

The lack of both employment stability and longterm labor contracts lowers their willingness to participate in any insurance (Lasimbang et al., 2016). Moreover, it reduces their chance in accessing healthcare. This makes them a vulnerable group in Indonesia's national health insurance system. The irregular status of residence combined with low social-economic condition of blue-collar migrant workers increases the insecurities of their employment, income and causes restrictions to their access to healthcare. This group of workers seems to come across social stigma, cost and legal status as barriers in accessing healthcare (Qin et al., 2014). Various health problems have already been reported in many studies experienced by the blue-collar migrant workers.

The white-collar migrant workers tend to have more ability to access the healthcare due to the fact that they have higher social-economic conditions and the national regulations which make it mandatory for the employers to pay for their health insurance. After the implementation of national health insurance in 2014, Indonesia performs uniform insurance which is compulsory for its population. It brings migrant workers to the decision about whether they should choose to remain only on primary healthcare facility according to their participation in national health insurance. Even though portability is warranted by the national health insurance agency, it is only for emergency situations. Their out of date identity documents cause various institutional restrictions. This will lead to lower insurance participation rates compared to other populations (Van Den Akker \& Van Roosmalen, 2016).

Maternal mortality occur more often in migrant workers in most cases when compared to the local population (Van Den Akker \& Van Roosmalen, 2016). Those without a legal resident permit are most vulnerable. Both health workers and social workers in our study said that there are many obstacles in managing maternal healthcare for urban migrant workers. Besides, the updating of legal residency will ruin the healthcare access, and it also hinders urban migrants' ability to socialize well with the localities. Social workers should communicate more actively to helping this group. This is indicated by the suboptimal participation of urban workers in antenatal care. Migrant women were often having a late first antenatal booking. Limited access to full labor rights and the experiences of social stigma, discrimination and inequity were the most significant factors which hamper the women migrants' access to the healthcare services (Li \& Rose 2017).

Improving the familiarity of women migrants to healthcare workers should be done in order to help them minimize disparities in access to maternity care (Fleischman et al., 2015). This recommendation has already been implemented in Indonesia through the existence of the social workers. The social workers' role is a Communication Bridge between health workers and pregnant migrants. Unfortunately, they find it hard to communicate with this group, as this group tends to be "hidden" or "accidentally hidden" from localities. Most of the migrants are working, so they use this reason for their absence from community meetings with localities. Whether there is an existence of social stigma which hinders this group openness should be studied in future research.

Our study also found some issues regarding the capability of the supply of managing maternal healthcare for urban migrants. In this case, the white-collar should be excluded from our discussion because they have national health insurance which makes it easier for them to get referral healthcare. Inconsistency between their primary health care locations with their current location will be easily diminished due to their economic ability to access 
primary healthcare. The problematic issues came out in the blue-collar workers. We have already explained that they will be restricted by their legal documents to encourage social assistance from local government. The current local government might not help them because they still belong as a resident in their hometown. Our findings show that health workers have a dilemma when they should refer the high risk expectant mother to the hospital. This population does not have any ability to pay the health care fee for services received; moreover they also do not have any health insurance. However, as they are health workers in the Public Health Center, these health workers could barely leave this population untreated. Surprisingly, all of the midwives in our study agreed that financial accessibility is not the main reason for the high number of maternal problems in this population. They tend to blame inappropriate planning and financing of migrants' management in the government health institution as the main root cause.

\section{CONCLUSIONS}

Blue-collar workers are the most vulnerable population in urban-to-rural migrants. Their absence in the national health insurance recipients combined with their low social-economic condition, which then creates health disparities when compared to the locals, compounds this problem. Even though whitecollar migrants are in a better condition, they are threatened to be unable to use the free healthcare services if they do not update their identity documents with current residency information. Social workers serve as the communicators of urban migrants to the primary healthcare workers. This successfully minimizes the passive communication of urban migrants in order to get the optimal antenatal, maternity, and post-natal care, but fails to communicate with the referral health service due to legality representation. Whereas primary health care facilities facilitated the urban migrants' health need, their effort was restricted by the administration requirements in accessing free healthcare service using national health insurance. This study suggests that each local government should be proactive in monitoring their migrants' population. Cooperation between local governments should be strengthened to accommodate the updating of identity documents for migrants.

\section{ACKNOWLEDGEMENTS}

We would like to express our appreciation to the Faculty of Public Health at Universitas Airlangga for their financial support in this conference.

\section{REFERENCES}

Fleischman, Y. et al., 2015. Migration as a social determinant of health for irregular migrants: Israel as case study. Social Science and Medicine, 147(2015), pp.89-97. Available at: http://dx.doi.org/10.1016/j.socscimed.2015.10.046.

Gao, Q., Yang, S. \& Li, S., 2012. Labor contracts and social insurance participation among migrant workers in China. China Economic Review, 23(4), pp.1195$1205 . \quad$ Available at http://dx.doi.org/10.1016/j.chieco.2012.09.002.

Lasimbang, H.B., Tong, W.T. \& Low, W.Y., 2016. Migrant workers in Sabah, East Malaysia: The importance of legislation and policy to uphold equity on sexual and reproductive health and rights. Best Practice and Research: Clinical Obstetrics and Gynaecology, 32(2015), pp.113-123. Available at: http://dx.doi.org/10.1016/j.bpobgyn.2015.08.015.

Li, J. \& Rose, N., 2017. Urban social exclusion and mental health of China's rural-urban migrants - A review and call for research. Health and Place, 48(May), pp.20 $30 . \quad$ Available at: http://dx.doi.org/10.1016/j.healthplace.2017.08.009.

Qin, X., Pan, J. \& Liu, G.G., 2014. Does participating in health insurance benefit the migrant workers in China? An empirical investigation. China Economic Review, 30, pp.263-278. Available at: http://dx.doi.org/10.1016/j.chieco.2014.07.009.

Van Den Akker, T. \& Van Roosmalen, J., 2016. Maternal mortality and severe morbidity in a migration perspective. Best Practice and Research: Clinical Obstetrics and Gynaecology, 32, pp.26-38. Available at: http://dx.doi.org/10.1016/j.bpobgyn.2015.08.016. 